\title{
Mediating Close Friendship Intimacy in Times of (Social) Distance
}

\author{
JEANNINE TEICHERT, Paderborn University
}

\begin{abstract}
This article explores mediated intimacy in distant close friendships as a necessary but challenging course of action to bridge physical absence. Linking media and communication studies with migration research, which often studies the mediation of intimacy of transnational family members and their communicative habits, this study examines how mediated communication differs between distant close friends and translocal families. In this respect, communication media are helpful to keep up existing friendships from a distance. However, due to their mediated nature, they offer an illusory feeling of intimacy that cannot compete with face-to-face interaction. This article explores communicative friendship exchange in times of social distance by drawing on German case studies in pre-pandemic times. It examines how mediated intimacy is reproduced in distant close friendships by offering emotional or mental support and bridging physical distance via communication media to outline potentials in times of pandemic-related social distancing restrictions. The study presented in this article contributes to the discussion of mediated intimacy, and highlights potential opportunities to enhance physically distanced friendships in post-pandemic times.
\end{abstract}

\section{KEYWORDS}

Mediated intimacy, Friendship, Social distance, Everyday life, Distant close friends

\section{Introduction}

In times of social distancing, communication technologies become even more crucial in geographically distant friendships to bridge the physical distance. In contrast to translocal families, which usually have at least one mutual place of living, friendships are supposed to be well equipped for digitally mediated maintenance due to their independent constitution of place and time (Nötzold-Linden 1994, 146). Moreover, friendships can quickly adapt to personal life changes (Nötzold-Linden 1994, 219) and could be kept through communication technologies. Despite their differences in social structures and categories, translocal families and distant friends often use digital media to interact with each other from afar. Migration research, at the centre of analysis of distant relationships, however, has primarily focused on how translocal family members connect and maintain their bonds with communication media across geographical distances (Diminescu 2008, Leurs 2015, Madianou and Miller 2012). Less is known about how distant friends negotiate their relationships. 
With regard to the COVID-19 pandemic, the question arises of how close friends communicate via media in times of social distancing. Distant loose friendships often continue to exist even if there is less or no communication taking place at all (Teichert 2020). On the other hand, distant close friends can interpret the absence of digital communication or its deliberate refusal as a personal rejection and, in the long run, even dissolve a relationship. In this article, I contrast translocal families' digital communication as an example of extensive use of synchronous media with that of distant close friends who prefer short, asynchronous, and sporadic ways of communication. Outlining the benefits and affordances of translocal family communication allows me to suggest hidden potentials of digital communication for distant close friendships, especially in times of social distancing. Grounded in a social constructionist mediatization approach (Hepp 2020, Krotz 2001), this paper looks at communication media's value to produce mediated intimacy in distant close friendships.

\section{(Deep) mediatization of distant relationships}

The process of mediatization refers to an open, ongoing discourse of theorizing the social and cultural transformation concerning media and communication (Hepp 2020, 9). Mediatization does not take place selectively (Hepp 2020,10) but as a "meta-process" of societal change (Krotz 2007a, 256). This is reflected in changing communicative habits and social and cultural conditions of human coexistence (Krotz 2001, 33). People use new technologies to communicate and turn them into "media" by creating the need and demand for societal change, as Friedrich Krotz (2007b, 31, 47-48) states. Thereby, the process of mediatization (Hepp and Krotz 2012, 9) emerges. As a meta-process, mediatization occurs in the background and is reciprocally produced by mediated human actions and practices and influenced by them (Hepp and Krotz 2012, 9, Krotz 2007b, 31). Thus, mediatization is both part of, and expressed through, everyday culture (Couldry and Hepp 2017, 35).

Mediatization as a process, according to Couldry and Hepp $(2017,34,41)$, can be retraced to the past five to six centuries. After the era of mechanisation and electrification, the period of digitalisation began around 1950 with digital communication and continues today in terms of virtual social networks and mobile technological devices (Couldry and Hepp 2017, 48-51). Currently, the scientific discourse discusses another phase, the so-called "datafication" that Couldry and Hepp $(2017,34)$ characterise by an increased accumulation of personal data. The phases of digitalisation and datafication can be located in the concept "deep mediatization" (Couldry and Hepp 2017, 34). In this paper, I apply the understanding of mediatization as a "meta-process" of social change (Krotz 2007a, 256) and the construct of "deep mediatization" (Hepp 2020) as a temporal definition of this process. In this respect, I explore communication media's role as a facilitator of social and individual mobility and, consequently, as a prerequisite to producing mediated intimacy in distant close friendships. 


\section{Intimacy negotiations in translocal families}

To examine how close friends maintain intimacy over physical distance, I compare translocal families' interactions, a key theme in migration research, with distant friendship communication to explore similarities and differences. Translocal families have a long tradition of establishing proximity and intimacy by communication media, in the past by letter writing (Greschke 2014, 156) and today increasingly by mutual online interaction (Miller et al. 2016, 105). Family migration research in this vein has focused mainly on the mediated negotiation of intimacy by referring to communication media's technical adaptation (Chambers 2013, 112) but the actual production and negotiation of mediated intimacy between family members remain unexplained (Greschke 2014, 158-159). In this regard, translocal and transnational families report positive effects, for example, by using visual media components to communicate with family members left behind. Video chats help see children and grandchildren growing up (Francisco 2015, 181) and parenting from afar (Francisco 2015, 188). In translocal parent-child relations, frequent contact seems to be an essential factor in keeping up the family communication. Furthermore, communication about their everyday life seems to matter to negotiate family relations continuously.

When migrant parents become foreign workers, they often report a feeling of duty and necessity to care financially and emotionally from afar. Also, adult children who moved abroad perceive these responsibilities and duties, helping their families financially and checking on their parents' health condition and well-being by calling home often (Horst 2006, 149). Particularly synchronous mediated communication with migrated family members "can generate feelings of proximity despite geographical distance", as Jay Marlowe et al. $(2017,93)$ conclude in their study. The everyday use of digital media technologies facilitates keeping up intimate relations with family members abroad. Close relationships can be maintained via digital co-presence across distances. However, the perceived mediated intimacy might also provoke the desire for face-to-face interaction. Accordingly, as Hall $(2020,104)$ states, people feel less lonely after face-to-face interactions than after exchanging text and voice messages or video chats with their close ties. Hales and Caton $(2017,103)$ emphasise this effect in their autoethnographic study on aeroplane travelling for business and family reasons. As Hales and Caton argue, taking a plane to meet face to face with one's family members can be morally justified, although environmentally questionable, if the family lives far away from one's workplace. Hence, face-to-face communication provides a more intimate and close connection than communication media can enable.

Although families and friendships are both based on close intimate connections, friendships differ from families regarding their actual and perceived duties and obligations (Allan 1979, Nötzold-Linden 1994, 11, Rawlins 2009, 9). Family relations are maintained by law (Blatterer 2016, 66, Rawlins 2009, 9), even if members live in different countries. On the other hand, friends are not obliged to take care of persons left behind and can even dissolve friendships in their absence. However, close friends can voluntarily support each other emotionally (Allan 1989, 83, Blatterer 2016, 63, Hansen 2009, 237) and financially (Allan 1989, 51-52, Rawlins 
2009, 13, Wiseman 1986, 204-205). Hence, there is need to particularly address how distant close friends negotiate mediated intimacy through media communication.

\section{Mediating intimacy in distant close friendships}

In contrast to families, friendships depend on a continuous reassurance of their reciprocally perpetuated relation via media because of the missing legal bond and the non-existent attachment to a physical place to constantly reproduce conditions for digital intimacy. Consequently, mediated proximity cannot be taken for granted as a pre-existing unit of measurement, it must always be negotiated (Sheller and Urry 2006, 8). Across physical distances, it becomes more challenging to negotiate and maintain intimacy and trust (Harrison 1998, 98-100, Miller et al. 2016, 105), particularly during pandemic-related social restrictions, if these actions have mainly taken place face to face before. Communication media allow specific actions but render others improbable or impossible (Deppermann et al. 2016, 5). Hence, it becomes more complicated for friends to negotiate the terms and conditions of their friendship, such as being available face to face or via media in times of need.

Throughout this article, I refer to distant close friends as previously locally established close ties between two or more persons who perceive each other as mentally or emotionally particularly relevant. These meaningful close connections do not necessarily dissolve by spatial distances (Allan 1989, 19). In fact, as Mollenhorst et al. $(2014,73)$ found out, only one to three per cent of social relationships are severed by physical distance. Instead, a change of character or worldviews can be considered as a relevant reason for a friendship break-up, specifically after periods of physical absence (Wiseman 1986, 200-201). Based on "strong ties", as Mark S. Granovetter (1973) labelled these connections, distant close friends share the desire to care for and support each other even from afar. By shifting physical co-presence to mediated copresence (Sheller and Urry 2006, 3-4), distant close friends can use a range of (digital) media technologies to substitute the lack of face-to-face interactions (Gomes et al. 2014, 2), provided communication media are perceived reciprocally as a means of maintaining a relationship.

However, the current shift towards asynchronous forms of digitally mediated communication, such as short texts and voice messages significantly decreases communicative interactions in friendships. Short messages often convey trivial content and the negotiation of new face-toface appointments (Church and Oliveira 2013, 355, Mannell 2020, 282). Although constantly checking for new messages on smartphones has now been established as a social practice of connectedness (Bayer et al. 2016, 128), an existing mediated connection to distant close friends does not seem to be synonymous with an actual negotiation of friendship. Compared to families, who communicate frequently and synchronously via media due to their perceived and actual duties and responsibilities to care for each other, distant close friends communicate less in digital environments because of the missing connection to each other's everyday life. Friends choose to interact irregularly via asynchronous short messages instead of reconstructing their intimate relations in everyday mediated co-presence. Nevertheless, distant close friends can 
still influence each other's thinking and behaviour, as Magret Hansen $(2009,196)$ points out, even if there is no communicative interaction taking place.

In terms of mediated intimacy, the dichotomy between the desire for face-to-face interaction and the reciprocal negotiation via asynchronous media communication is reinforced in distant close friendships. Mediated intimacy is defined by Feona Attwood et al. (2017) as requiring a (digital) medium to form an intimate relationship between humans. The continuous (re)production of intimacy, in turn, is understood according to David Morgan $(2013,35)$ across three dimensions: first, as a physical expression, for instance, to touch someone's arm; second, as emotional trust in terms of non-verbal understanding, and third, as private biographical information that builds up over time. The intimacy dimensions mirror the quality of a relationship and differ in terms of their embodiment in every relationship (Morgan 2013, 35). Hence, if the continuous reproduction of intimacy across distances increasingly takes place via communication media, it becomes evident that communication media indeed can help to build emotional trust between individuals and to expand intimate knowledge about one another. However, media cannot replace the haptic feelings of a face-to-face interaction yet. Therefore, the process of mediatization (Krotz 2001) supports not only social mobility but also influences the conditions for the reproduction of mediated intimacy in distant friendships. New digital technologies and apps for short and asynchronous communication enable distant close friends to rely on their previously established intimate connections. However, they hinder friends' considerations to renew and renegotiate their fragile relationships in synchronous mediated interactions, as, in comparison, family members regularly do. Subsequently, I explore how mediated intimacy is reproduced in distant close friendships by providing emotional or mental support and bridging physical distance via communication media to outline potentials in times of pandemic-related social distancing restrictions.

\section{Methodological approach and data analysis}

Drawing on empirical findings of a recent dissertation study on mediated friendship negotiations in Germany, 25 in-depth life history interviews (Fuchs-Heinritz 2009, Küsters 2009) conducted in 2017 and 2018 provide insight into memories and recent friendship experiences of 14 male and 11 female job entrants, aged between 22 and 37 . The study followed the Grounded Theory approach and methodological framework of Strauss and Corbin (1996), respectively Corbin and Strauss (2015), and the guiding principles of theoretical sampling and memo writing along with the research process. Following Corbin and Strauss (2015), constant theoretical sampling took place in the three stages of open, axial and selective coding during participant recruitment and subsequent interview transcription, data analysis and interpretation. The dissertation study aimed to present a diverse sample in terms of professional backgrounds and work experience, media usage and number of friends to ensure the richness and variety of the selected data, as Strauss and Corbin (1996, 155-156) suggest. Interviews took place at the participants' preference, either at their homes or workplaces, at universities or outdoors, to ensure a calm and quiet atmosphere. The interview length was between 90 minutes to 140 
minutes. Major topics included the participant's personal definition of friendship and past and current friends to explore individual meanings that shaped the basis for their friendships. In terms of media use and mediated negotiation of friendships, questions covered communication apps and time intervals for reciprocal media communication and face-to-face meetings. The interview data was transcribed and coded via QDA software. During the interviews, participants were asked to draw, write or sketch a self-centred map of their friends' network (cf. Hollstein and Pfeffer 2010, Straus 2006). For seven days after the interview, participants were also asked to fill in media diaries (cf. Berg and Düvel 2012) to visualise and complement their previous narration. All data was pseudonymised, and all interview sections were translated from German to English, while linguistic expressions of the interviewees were kept where possible.

In this article, the mediation of intimacy in distant close friendships is presented by case studies of three female participants. These case studies were specifically chosen to demonstrate the strength of their distant close ties in comparison to their otherwise loose local social networks. The core categories developed from the Grounded Theory data analysis regarding mediated intimacies encompass distant intimacy, mediated everyday intimacy and tacit intimacy. These types of intimacy mediation in friendships differ in terms of their communicative negotiation. Distant intimacy, for example, stands out due to the significant emotional value of an intimate connection to a distant close friend that prevents the formation of new local social bonds. Mediated everyday intimacy characterises the communicative exchange of everyday inanities via media between distant close friends to maintain a previously locally established level of intimacy. Lastly, tacit intimacy describes how distant close friends still rely on each other, even though their communicative interaction is minimal. All categories presented in this paper are exemplified by the three participants' narrative construction of their distant close friendships.

\section{Findings}

\section{Mediating intimacy across distances}

As explained above, the mutual negotiation of friendships differs along with the availability and use of media repertoires and becomes more difficult the less distant close friends are integrated into each other's local everyday life. While Hall argues, mobile media allows you to "take your family and friends with you wherever you go" $(2020,189)$, this study's empirical findings suggest that intimacy negotiations in distant close friendships are not based on obligations to talk frequently and to discuss important life decisions, in contrast to family relations, as presented earlier in the literature review. Instead, distant close friends live on their previously established intimacy experiences. First of all, their communicative exchange takes place less frequently. Second, these interactions are often based on trivial topics aiming to reassure and maintain an established intimate relationship. Discussing everyday life issues, as translocal families do for the continuous reproduction of intimacy, is often omitted in distant close friendships. Although silence and less frequent digitally mediated interaction can be seen 
as expressions of intimacy, they can also reveal feelings of exclusion and loneliness due to missing physical and synchronous media interactions. The female participants selected for the purposes of this article, Sandra, Isabelle and Vanessa, reflect particularly well the dimensions of the three types of intimacy mediation, distant intimacy, mediated everyday intimacy, and tacit intimacy.

\section{Alone among strangers: Distant intimacy}

When close friendships are maintained across time zones and world regions, space- and timerelated experiences change (Sheller and Urry 2006, 7). Distant close friends might experience "distant intimacy" (Lambert 2013, 77-78, Raphael and Epstein 2013), reinforcing the dichotomy between the desire for face-to-face interactions with close ties in spatial separation and the inclusion in a local circle of friends. Dance educationist Sandra, 27, characterises the friendship with her three distant close friends, Clea, Mai, and Tea, who live in Belgium, as a "deep connection with soulmates". Her three close friends have a tremendous emotional significance for Sandra because, in her opinion, these are friends with whom she "really connects deeply", which she does not often find within her local environment. As she reports, "then I'd rather have [...] no connection, than one where I actually think, that doesn't really interest me at all". Sandra has difficulties dealing with a current health issue that prevents her from attending dance events and visiting her international friends more often.

Sandra: "Well, they have crystallised out for me, because I realised [...] I talk to them about the fact that it's hard for me, that I can't participate anymore because of my health. [...] And actually, eighty per cent of my social network is somehow almost no longer accessible and $[\ldots]$ that is definitely totally difficult for me. [...] Because I also feel lonely and somehow try to establish connections in my shared apartment. But now I also noticed, despite they are all super nice [...] that's not enough for me (laughter). [...] That's just not enough. [...] I spend relatively little time with friends somehow. So, I do have $[\ldots]$ work and, and therefore/ in any case, this summer I withdrew from almost everyone $[\ldots]$ Because there is no fixed circle [of friends] where [...] we meet regularly or something like that."

In her local environment, she mainly focuses on work and "spends relatively little time with friends" because she does not find the same level of deep emotional connections in her local social network that she created with her three friends abroad. Sandra feels lonely and isolated. Meanwhile, she tries "to see any one of the three [distant close friends] around once a month". She bridges the time until the next reunion with telephone calls, text and voice messages. Nevertheless, media communication is no substitute for Sandra's lack of face-to-face contact with her three soulmates. Thus, it is easier to cope with the feeling of loneliness when friends mutually know that they will meet face to face again in the foreseeable future (O'Hara et al. $2014,11)$. Only by combining digitally mediated interaction with regular visits to her distant close friends in Belgium, does Sandra experience ongoing negotiations on all three dimensions of intimacy, as stated by Morgan $(2013,35)$, that enable her to focus more closely on these relationships. The lack of close local friendships, in turn, leads to an increase of distant 
intimacy for Sandra. She reaches out for emotional support to her distant close friends via communication media as often as possible, while in her local offline world, she feels alone among strangers.

\section{Dissolved local networks: Mediated everyday intimacy}

HR manager Isabelle, 31, provides an example for mediated everyday intimacy by exchanging everyday occurrences on instant messenger to re-establish her close friendship bond perpetually with one of her distant close friends. Isabelle's previously close local friendships repeatedly dissolved and changed to translocal friendships in the past. Now, many of her distant close ties live in other regions of Germany or even abroad. Hence, Isabelle must resort to communication media to compensate for her distant friendships' lack of physical intimacy. However, she is not very enthusiastic about implementing media communication to bridge the missing haptic exchanges. As she says, she "hates" voice messages, and she "does not want to type that much either". Isabelle explains, "it's just not that I would pick up the phone/ I probably wouldn't do that anyway [...] pick up the phone and say something like, "I need some support right now", so that's kind of not my thing". Instead, Isabelle travels several times a year to visit her close friends. As she only experiences "a slice of life" of her distant close friends' everyday life, she labels this type of relationship a "weekend friendship". Nevertheless, she says, she misses "this continuity, that you always know what's going on and that you are always very, very close". Only with her distant close friend Hilke, who currently lives in Luxembourg, Isabelle experiences an enjoyable "WhatsApp exchange over distance, once a month or so", by text and voice messages and voiceover IP calls.

Isabelle: "[Hilke is] someone with whom you can also easily exchange such trivial stuff $[\ldots]$ So there is a connection that is not terse [...] but that is really nice when she explains to me, "Here, I bought a drilling machine." And I'm like, "Whoa, awesome. Fantastic. It looks really nice."”

With Hilke, Isabelle manages to assure emotional trust and intimate knowledge, two of Morgan's $(2013,35)$ intimacy dimensions, by exchanging trivial messages. The virtual witnessing of Hilke's everyday life, exemplified by their communication about the purchase of a drilling machine, demonstrates their particular communicative level of friendship intimacy that is constantly renewed and reproduced. Although the two friends cannot meet face to face to try the new drilling machine, Isabelle probably knows about Hilke's necessity to buy a new one due to their continuous exchange of everyday inanities. Despite the distance between Germany and Luxembourg, Isabelle and Hilke enable each other's virtual participation in their friend's everyday life via communication media and thus, continue to create and maintain emotional trust and intimate knowledge. In addition to that, the friends also maintain Morgan's $(2013,35)$ third dimension of physical expression by reciprocal physical resonance (Rosa 2016, Wetzel 2014) through mutual visits, approximately six to seven times a year. Consequently, Isabelle's multiple weekend trips to her distant close friend Hilke help her to compensate for the lack of physical friendship intimacy in her everyday life. However, it also becomes evident 
that Isabelle and Hilke's connection is an exceptional one, which Isabelle does not share with many other local or distant friends.

\section{"You know they are there": Tacit intimacy}

Maintaining intimacy with distant close friends on a day-to-day basis is a time- and energyconsuming task. Commercial clerk Vanessa, 23, highlights this discrepancy. In Vanessa's view, a friendship nowadays "doesn't have to happen in person anymore". Sometimes, she even gives preference to asynchronous media interaction with her distant friends over face-to-face meetings. Although Vanessa established a loose local network of friends at her current place of residence, her distant close friend Sabrina, who moved a few hundred kilometres away, seems to be more important to Vanessa than her local friends. Vanessa and Sabrina are in contact virtually about every three months - whenever Vanessa reaches out for Sabrina's support as a tacit distant friend.

Vanessa: "It can happen that I grab my mobile phone at eight or nine in the evening and say, "Man, I am in a REALLY shitty place right now", and when she's on her mobile or somehow online or notices my message or even a day later, she replies immediately, "Man, don't look at it so negatively. You have this and that positive". You always know each other a little bit. So, she says, "Man, you've done so much", and so. Well. Everything goes on, you exchange ideas and you also just help each other, just by writing. Just by writing, just so/ just exchanging, just also having an outlet like that. So, like I said, it's basically when you're feeling like crap. You can either sit at home and cry alone into your pillow, for example or somehow break the TV or whatever. [...] Somehow let out the aggression, anger or joy or whatever. But if you can share that, if you can really share that with someone. Just write it down like that, that's already [...] friendship for me, like that. And as I said, you just, you don't have to see each other for that, you don't have to meet each other for that. It can follow in writing, as I said. And that is [...] an invisible bond, which connects you [...]. I don't know when I will meet them next time, how long the contact will last or so, but you know they are there."

This "invisible bond" between the two friends, which Vanessa outlines in this excerpt, consists mainly of exchanging asynchronous text messages. Despite the lack of face-to-face contact between the two, Vanessa manages to connect with her distant close friend, as long as Sabrina reciprocally reacts to Vanessa's requests. Even if this does not happen until the following day, Vanessa relies on her friend to provide her with the emotional strength she seeks by reaching out. In this case, Vanessa's omnipresent inclusion of instant messenger in her everyday life becomes evident. Instead of calling her friend Sabrina or contacting one of her loose local friends, she rather sends a text message to her distant close friend and waits for a delayed response. Tacit intimacy develops implicitly between the two. Vanessa does not share everyday inanities with Sabrina, as Isabelle does, nor does she withdraw entirely from her local social network, as Sandra does. In Vanessa's perception, face-to-face contact to establish and reproduce intimacy is not necessary in distant close friendships anymore. It is more convenient for Vanessa to reach out to her distant close friend when she requires an instant intimacy 
affirmation. In the meantime, she remains more or less detached from Sabrina's everyday life. In this case, Vanessa's and Sabrina's friendship intimacy is based on emotional trust and intimate knowledge about each other, according to Morgan's $(2013,35)$ understanding. However, their intimacy negotiations mainly refer to past experiences, as Vanessa expresses. Instead of inclusion of new mediated or physical intimacy by communicatively exchanging about each other's everyday life, as translocal families do, their previously established emotional trust diminishes to a brief mediated reassurance of a friendship that is primarily based on the past.

\section{Discussion: A balancing act between silence and demand}

In times of "deep mediatization" (Hepp 2020), digital communication media facilitate the mediated connection of translocal families and distant close friends. Contrary to translocal family communication, it becomes apparent that significantly less digitally mediated interaction takes place within distant close friendships. Distant friends ask less for mental, emotional or financial support than translocal family members. In migrated families, help is actively provided and demanded. As shown above, distant close friendships are not based on obligations to communicate and care for each other. Instead, they depend on previously established mental or emotional connections that are secured and kept alive by short and sporadic media communication. Sandra and Isabelle experience a constant desire for face-toface interaction with their distant close friends to renew their previously established intimacy and trust. Vanessa, in contrast, explains the potential of distant mediated availability with her close friend Sabrina that works well, as long as Sabrina reacts timely to Vanessa's request. Thus, we can observe a decrease in the conversational nature of distant close friendships. The differentiation between sociality within loose local friendships and mediated intimacy with distant close friends becomes apparent when looking at the participants' approaches to faceto-face versus digitally mediated communication. Although the study's participants might have urgent support needs to talk and exchange with closely connected friends, it does often not occur to them to ask their distant close friends for instant synchronous communication. Instead, they would rather send a short text message and wait for their distant close friend's reply. As Isabelle stated, she does not "pick up the phone" to request her friend's emotional support. The demand for mental or emotional intimate conversations with distant close friends via media seems to be a difficult task. Although living in physical distance, close friends continue to communicate on intimate topics in person rather than via media.

Consequently, media communication with distant close friends is often used as a reminder of an existing relationship. However, an extensive emotional or mental exchange is mainly reserved for face-to-face encounters. The feeling of proximity between distant close friends depends heavily on the actual denegation to use existing media technologies to renegotiate intimacy virtually. This phenomenon can be experienced and reinforced in times of social distancing, associated with a deceptive feeling of mediated proximity, when individuals necessarily communicate less face to face and more via media. For instance, during the 
COVID-19 pandemic, the third dimension of intimacy production, according to Morgan (2013, 35 ) the physical expression, is even more at risk in distant friendships, as travelling and social restrictions dominate everyone's life in conditions of lockdown. Hence, the mediation of intimacy in friendships could either shift even more to a digitally mediated level or decrease further. In this respect, it is imaginable that distant close friendships align themselves more closely with migrant families' daily and synchronous communication habits to extend the feeling of digitally mediated intimacy when face-to-face interactions are challenging to realise. Synchronous media communication, for instance, calling or video chatting, has proven to be a successful measure for migrant families (Francisco 2015, Miller et al. 2016). Thus, it can be beneficial to re-establishing intimacy in friendships in times of social distancing.

As illustrated by the case of migrant families, integrating each other into one's everyday life can create awareness when distant close friends are needed the most. A missing local social network and pandemic-related restrictions on face-to-face interactions can be mentally and emotionally challenging. If friends continue to exclude everyday conversations from their current sporadic virtual asynchronous communication, the situation Isabelle and Vanessa describe is most likely to happen in other distant close friendships as well: in a specific moment of need, distant close friends either do not reach out to call their close friends or they send a short text message and wait for their friend to get back to them at their convenience without actually conversing with each other about the underlying reason for the contact initiated. A quick and brief reaction to a friend's need for communication helps in the specific situation to produce tacit intimacy. Nevertheless, distant close friends who do not have a supportive local social network can use the entire communication media repertoire to engage in everyday conversations with their distant close ties, instead of texting at one's convenience, to overcome the potential feeling of isolation and loneliness. The further friends become emotionally distant from each other, and the more fragmented their communication actions, the more difficult it is probably to maintain a mutual willingness to communicate and to reciprocally share with each other, especially if the delay of responding increases by asynchronous communication in times of deep mediatization.

Finally, the study's limitations should be pointed out. First, it is important to consider that not every distant friend is supposed to catch up with their entire social network near and far at all times. The case studies presented disclose the importance of distant close friends if the local social network is based on loose connections. Second, the cultural embedding in Germany might influence participants' perception and the underlying cultural understanding of friendships and friendship communication, which cannot be transferred to other cultures without considering the specific value and connotation of friendship. Third, as the data gathering took place in pre-pandemic times, further research can explore the consequences of social distancing during, and after, the COVID-19 pandemic to compare retrospectively if and how a potential shift to a largely digitally mediated communication, necessitated by life in lockdown, occurs in distant close friendships. 


\section{Conclusion}

This article presents the mediation of intimacy in distant close friendships and discusses physical distancing's potential consequences. Grounded in the literature on migrated family members' remote communication repertoires, their communicative negotiation of intimacy, perceived obligations and care for each other despite geographical distances, this article explored how distant close friends in comparison exchange news and requests for emotional and mental support via communication media. Although previously local close friendships often transform into translocal connections, missing in-depth conversations and intimacy negotiations further the feeling of isolation during social distance that might be overcome by more explicit synchronous media use in distant close friendships.

Concerning the reproduction of mediated intimacy in distant close friendships, three distinct dimensions arise from the empirical data that have relevance to mediated friendships in the COVID-19 pandemic: distant intimacy, mediated everyday intimacy and tacit intimacy. The dimension of distant intimacy reflects a longing for face-to-face interaction to receive emotional support from distant close friends that cannot be compensated by media communication or by a loose local network of acquaintances, as exemplified by the case of dance educationist Sandra. Mediated everyday intimacy is expressed by Isabelle's case through a continuous exchange of short and trivial messages that are complemented by regular face-toface encounters to remind and continuously renew a previously established level of friendship intimacy, despite the social distance while physical encounters are reserved for meaningful conversations. Lastly, Vanessa's case demonstrates how the lack of mediated and face-to-face communication manifests in tacit intimacy, reflected by spontaneous reactivation requests for emotional support. Although all mediated intimacy dimensions discussed above mirror Morgan's $(2013,35)$ interpretation of the two dimensions of emotional trust and private information, the missing third dimension, physical intimacy, cannot be replaced entirely via media in times of social distance. Both Sandra and Isabelle expressed their desire for face-toface contact with their distant close friends, although these encounters are limited to a few per year.

In conclusion, three primary outcomes of this study should be summarised in light of intimacy mediation during the COVID-19 pandemic, which is characterised by limited possibilities for face-to-face interaction. First, the gravity of the pandemic highlights the importance of taking responsibility for, and nurturing, close friendships if they wish to preserve them. Although there is no legally binding and official duty to take care of each other, close friends often are concerned, and they often want to provide mental or emotional support to their closely connected distant friends. Second, if individuals are not aware of a friend's emotional or mental issues near or far, they cannot help them in times of need. Third, using digital media for synchronous interaction in times of physical distancing and actively asking for, and providing, help to a distant close friend might enhance the experience of mediated intimacy in friendships, as exemplified with translocal family communication. Relevant topics and emotional issues in friendships are often not exchanged via communication media but rather in face-to-face interactions. However, in times of social distance, they cannot take place often. Mediated 
communication cannot substitute intimate face-to-face encounters with close friends entirely, but it can help to decrease the feeling of loneliness in an increasingly mediatised world, and mainly in times of social distancing.

\section{References}

Allan, G. (1979) A Sociology of friendship and kinship. London: George Allen \& Unwin. Allan, G. (1989) Friendship. Developing a Sociological Perspective. New York: Harvester Wheatsheaf.

Attwood, F., Hakim, J. and Winch, A. (2017) Mediated intimacies: bodies, technologies and relationships. Journal of Gender Studies, 26(3), 249-253. https://doi.org/10.1080/09589236.2017.1297888

Bayer, J. B., Campbell, S. W. and Ling, R. (2016) Connection Cues: Activating the Norms and Habits of Social Connectedness. Communication Theory, 26(2), 128-149. https://doi.org/10.1111/comt.12090

Berg, M. and Düvel, C. (2012) Qualitative media diaries: An instrument for doing research from a mobile media ethnographic perspective. Interactions: Studies in Communication \& Culture, 3(1), 71-89. https://doi.org/10.1386/iscc.3.1.71 1

Blatterer, H. (2016) Intimacy as freedom: Friendship, gender and everyday life. Thesis Eleven, 132(1), 62-67. https://doi.org/10.1177/0725513615619503

Chambers, D. (2013) Social Media and Personal Relationships. Online Intimacies and Networked Friendship. Basingstoke: Palgrave Macmillan.

Church, K. and de Oliveira, R. (2013) What's up with WhatsApp? Comparing Mobile Instant Messaging Behaviors with Traditional SMS. MOBILE HCl - Collaboration and Communication, 352-361. https://doi.org/10.1145/2493190.2493225

Couldry, N. and Hepp, A. (2017) The Mediated Construction of Reality. Cambridge: Polity Press.

Corbin, J. M. and Strauss, A. L. (2015) Basics of qualitative research. Techniques and procedures for developing Grounded Theory (4th ed.). Los Angeles: SAGE.

Deppermann, A., Feilke, H. and Linke, A. (2016) Sprachliche und kommunikative Praktiken: Eine Annäherung aus linguistischer Sicht. in A. Deppermann, H. Feilke and A. Linke (eds.), Sprachliche und kommunikative Praktiken. Jahrbuch 2015. Berlin: Walter de Gruyter, pp. 1-24.

Diminescu, D. (2008) 'The connected migrant: an epistemological manifesto', Social Science Information, 47(4), 565-579. https://doi.org/10.1177/0539018408096447 
Francisco, V. (2015) “The Internet Is Magic': Technology, Intimacy and Transnational Families', Critical Sociology, 41(1), 173-190.

https://doi.org/10.1177/0896920513484602

Fuchs-Heinritz, W. (2009) Biographische Forschung. Eine Einführung in Praxis und Methoden (4. ed.). Wiesbaden: VS.

Gomes, C., Berry, M., Alzougool, B. and Chang, S. (2014) Home Away from home: International Students and their Identity-Based Social Networks in Australia. Journal of International Students, 4(1), 2-15. https://doi.org/10.32674/jis.v4i1.493

Granovetter, M. S. (1973) The strength of weak ties. The American Journal of Sociology, 78(6), 1360-1380. Available at: https://www.jstor.org/stable/2776392

Greschke, H. M. (2014) "Mein Smartphone ist mein Schatz". Intimität in transnationalen Familien. in K. Hahn (eds.), E<3Motion. Intimität in digitalen Medienkulturen. Wiesbaden: Springer VS, pp. 150-167.

Hales, R. and Caton, K. (2017) 'Proximity ethics, climate change and the flyer's dilemma: Ethical negotiations of the hypermobile traveller', Tourist Studies, 17(1), 94113. https://doi.org/10.1177/1468797616685650

Hall, J. A. (2020) Relating through technology. Everyday Social Interaction. Cambridge: Cambridge University Press.

Hansen, M. (2009) Freundinnen. Freundschaftserfahrungen in weiblichen Biographien. Münster: Waxmann.

Harrison, K. (1998) Rich friendships, affluent friends: middle-class practices of friendship. in R. G. Adams and G. Allan (eds.), Placing Friendship in context. Cambridge: Cambridge University Press, pp. 92-116.

Hepp, A. (2020) Deep Mediatization. London: Routledge.

Hepp, A. and Krotz, F. (2012) Mediatisierte Welten: Forschungsfelder und Beschreibungsansätze - Zur Einleitung. In F. Krotz and A. Hepp (eds.), Mediatisierte Welten. Forschungsfelder und Beschreibungsansätze. Wiesbaden: VS, pp. 7-23.

Hollstein, B. \& Pfeffer, J. (2010) Netzwerkkarten als Instrument zur Erhebung egozentrierter Netzwerke, In H.-G. Soeffner (eds.), Unsichere Zeiten: Herausforderungen gesellschaftlicher Transformationen. Verhandlungen des 34. Kongress der Deutschen Gesellschaft für Soziologie in Jena, CD-ROM, Wiesbaden: VS Verlag für Sozialwissenschaften. Available at: http://www.pfeffer.at/egonet/Hollstein\%20Pfeffer.pdf.

Horst H. (2006) The blessings and burdens of communication: cell phones in Jamaican transnational social fields. Global Networks 6(2), 143-159. https://doi.org/10.1111/j.1471-0374.2006.00138.x 
Krotz, F. (2001) Die Mediatisierung kommunikativen Handelns. Der Wandel von Alltag und sozialen Beziehungen, Kultur und Gesellschaft durch die Medien. Wiesbaden: Westdeutscher Verlag.

Krotz, F. (2007a) “The meta-process of 'mediatization' as a conceptual frame”. Global Media and Communication, 3(3), 256-260.

https://doi.org/10.1177/17427665070030030103

Krotz, F. (2007b) Mediatisierung. Fallstudien zum Wandel von Kommunikation. Wiesbaden: VS.

Küsters, I. (2009) Narrative Interviews. Grundlagen und Anwendungen (2nd ed.). Wiesbaden: VS.

Lambert, A. (2013) Intimacy and Friendship on Facebook. Basingstoke: Palgrave Macmillan.

Leurs, K. (2015) Digital Passages: Migrant Youth 2.0. Diaspora, Gender and Youth Cultural Intersections. Amsterdam University Press.

Madianou, M. and Miller, D. (2012) Migration and New Media. Transnational families and polymedia. London: Routledge.

Mannell, K. (2020). Plural and Porous: Reconceptualizing the Boundaries of Mobile Messaging Group Chats, Journal of Computer-Mediated Communication, 25(4), 274290. https://doi.org/10.1093/jcmc/zmaa007

Marlowe, J. M., Bartley, A. and Collins, F. (2017) 'Digital belongings: The intersections of social cohesion, connectivity and digital media', Ethnicities, 17(1), 85-102. https://doi.org/10.1177/1468796816654174

Miller, D., Costa, E., Haynes, N., McDonald, T., Nicolescu, R., Sinanan, J., Spyer, J., Venkatraman, S. and Wang, X. (2016) How the World Changed Social Media. London: UCL Press. Available at: http://www.jstor.org/stable/j.ctt1g69z35

Mollenhorst, G., Volker, B. and Flap, H. (2014) Changes in personal relationships: How social contexts affect the emergence and discontinuation of relationships. Social Networks, 37, 65-80, https://doi.org/10.1016/j.socnet.2013.12.003

Morgan, D. H. J. (2013) Rethinking Family Practices. Basingstoke: Palgrave Macmillan.

Nötzoldt-Linden, U. (1994) Freundschaft. Zur Thematisierung einer vernachlässigten soziologischen Kategorie. Opladen: Westdeutscher Verlag.

O'Hara K., Massimi M., Harper R., Rubens, S. and Morris, J. (2014) Everyday dwelling with WhatsApp. Proceedings of the th17 ACM conference on computer supported cooperative work and social computing- CSCW '14, 1131-1143. https://www.microsoft.com/en-us/research/publication/everyday-dwellingwithwhatsapp/ 
Raphael, F. and Epstein, J. (2013) Distant Intimacy. A friendship in the age of the Internet. New Haven: Yale University Press.

Rawlins, W. K. (2009) The Compass of Friendship. Narratives, Identities, and Dialogues. Los Angeles: SAGE.

Rosa, H. (2016) Resonanz. Eine Soziologie der Weltbeziehung. Berlin: Suhrkamp.

Sheller, M. and Urry, J. (2006) Introduction: Mobile Cities, Urban Mobilities. In M. Sheller and J. Urry (eds.), Mobile Technologies of the City. London: Routledge, pp. 117.

Spencer, L. and Pahl, R. (2006) Rethinking Friendship. Hidden Solidarities Today. Princeton: Princeton University Press.

Straus, F. (2006). Entwicklungslabor Qualitative Netzwerkforschung. in B. Hollstein and F. Straus (eds.), Qualitative Netzwerkanalyse. Konzepte Methoden, Anwendungen. Wiesbaden: VS Verlag, pp. 481-494.

Strauss, A. L. and Corbin, J. M. (1996) Grounded Theory. Grundlagen qualitativer Sozialforschung. Weinheim: Beltz.

Teichert, J. (2020) "Ich habe auch Facebook-Freunde" - Erinnerungspraktiken in vergangenen Freundschaften. merzWissenschaft, 6, 29-37.

Wiseman, J. P. (1986) Friendships: Bonds and Binds in a voluntary relationship. Journal of Social and Personal Relationships, 3(2), 191-211. https://doi.org/10.1177/0265407586032005

Wetzel, D. J. (2014) Freundschaft und mediale Vermittlung. Resonanzbeziehungen im Kontext gelingender Lebensführung. in K. Hahn (eds.), E<3Motion. Intimität in digitalen Medienkulturen. Wiesbaden: Springer VS, pp. 108-123.

\section{Biography}

Jeannine Teichert is a Research Associate at Paderborn University, Germany. Her research interests involve interpersonal and intergroup communication, media sociology and migration research with a special focus on friendship interaction.

E.: jeannine.teichert@uni-paderborn.de 